\title{
What is Your "Phytolith Load"? An Examination of the Potential for Cross-Contamination During Phytolith Extraction
}

\author{
Abigail Buffington ${ }^{1 *}$, Andrew Weiland ${ }^{1}$, Julia Arnold ${ }^{2}$, and Drew Arbogast ${ }^{3}$ \\ ${ }^{1}$ Department of Anthropology, The Ohio State University, Columbus OH, USA ${ }^{2}$ Department of Microbiology \& Department of \\ Molecular Genetics, The Ohio State University, Columbus OH, USA ${ }^{3}$ Department of Ecology, Evolution and Organismal \\ Biology, The Ohio State University, Columbus, $\mathrm{OH}, \mathrm{USA}$. \\ *buffington.27@osu.edu
}

\begin{abstract}
Phytoliths-amorphous opal silica bodies that form in living plant tissues-are assumed to be stable components of a soil matrix, minimally impacted by normal physical forces. This stability enables archaeologists to access an archive of prior vegetative landscapes when discrete horizons are recovered. However, there is a small chance of phytoliths moving in a laboratory setting via aeolian forces, especially after they have been isolated from other materials such as clay, organics, and carbonates, and when multiple samples are being processed simultaneously. As a result, an assessment of contamination risk on sample extraction is necessary for interpreting the results of phytolith analyses. We designed a study to test the potential for contamination on slides in two different locations of the phytolith laboratory. The results of our study inform how we can improve on phytolith processing protocols and analyses to reduce the potential effect of crosscontamination between samples.
\end{abstract}

Received June 22, 2017

OPENӘACCESS

Accepted November 3, 2017

DOI 10.14237/ebl.9.2.2018.955

Keywords Phytoliths, Contamination, Paleoethnobotany, Sediment analysis

Copyright (C) 2018 by the author(s); licensee Society of Ethnobiology. This is an open-access article distributed under the terms of the Creative Commons Attribution-NonCommercial 4.0 International Public License (https://creativecommons.org/licenses/by-nc/4.0), which permits non-commercial use, distribution, and reproduction in any medium, provided the original author and source are credited.

\section{Introduction}

Phytoliths_amorphous silica dioxide opal minerals formed in living plant cells, luminae, and intercellular spaces-are a useful proxy for reconstructing past ecologies and the development of landscapes, especially in terms of herbaceous taxa (Piperno 2006). Capable of producing localized signatures of past vegetative communities, phytoliths exhibit greater stability in sediments in comparison to other organic proxies such as pollen and starch grains. They exhibit little movement below the A horizon in a soil sequence and are durable to high thermal temperatures and acidic soil pH levels (Fishkis et al. 2010a, 2010b; Okamoto et al. 1957; Rovner 1983). As such, they have been used to address a range of questions principally in archaeology, but also in paleontology, paleoecology, and geology (e.g., Alexandre et al. 1997; Gobetz and Bozarth 2001; Golyeva et al. 1995; Rosen 1992). What is less studied is the threat posed by contamination during the extraction process itself in the laboratory (Parr et al.
2001). Such contamination can risk misinterpretation of paleovegetation records, particularly when analyzing samples contemporaneous with the development of plant agricultural economies. Phytolith analysis would benefit from a consensus on the potential for contamination during phytolith slide procedures.

In this paper, we present the results of an experiment conducted to determine the rate of phytolith mobility in the laboratory during the mounting process (Rosen and Weiner 1994). We utilized twelve sediment-originating samples collected from multiple phases at an archaeological siteManayzah-dated to the Early Holocene (9000-7000 yrs BP) and another twelve samples from burned landscape surfaces spanning the Early to Middle Holocene (7500-6000 yrs BP), all from the southern Jol region of Yemen (Crassard et al. 2006; McCorriston et al. 2001). We utilized this subset due to the high volume and diversity of phytoliths recovered in other samples from these contexts 
(Buffington et al. 2017). First, we argue for the necessity of such a study based on a review of phytolith mobility research presented in previous analyses. Next, we report the analyzed results of our experiment using univariate statistical methods, principally on the two variables: distance from the mounting locus and location of the process. Last, we argue that risk of contamination in the laboratory may be significant to the interpretation of phytolith assemblages. The cleanliness of the laboratory may also be a crucial factor, and laboratories engaging in this research should conduct experiments following this protocol to determine their own contaminant threshold.

\section{Literature Review}

The phytolith record preserved in soil reflects the assemblage of local vegetation that once existed. A number of factors impact the integrity of these assemblages in the soil matrix: primarily, dust, as soils erode, and the process of extraction itself. While testing and documenting the effect of contamination on laboratory phytolith processing is rare in the literature, the possibility of such contamination occurring is mentioned in a number of phytolith studies (Cabanes et al. 2011; Horrocks 2005; Lentfer $\&$ Boyd 2001; Parr 2002). This paper seeks to define a protocol for conducting contamination testing during the final phase of the extraction process, mounting, when phytoliths are isolated from other sediment components.

\section{Phytolith Mobility and Taphonomy in Soils}

After deposition, taphonomic processes affect the resulting sediment archive. While opal silica phytoliths feature a chemical bonding to surrounding sediments at the time of deposition, recent research has indicated there is low but consistent vertical mobility in soils $(\sim 40 \mathrm{~cm}$ depth) and horizontal mobility observable where fluvial forces (e.g., irrigation) are present (Fishkis et al. 2010a, 2010b; Madella and Lancelotti 2012; Piperno 2006). Fishkis and colleagues (2010a, 2010b) found that the morphology and size of phytoliths can affect their translocation in soils (phytoliths with an aspect ratio $>3$ or an axis length of $<7.5 \mu \mathrm{m}$ increase with depth). Therefore, we might expect smaller, squarer morphotypes to predominate in any contaminated slides. Within soils, phytoliths do not necessarily remain in the same form as in their original deposition. Opaline phytoliths are resistant to acid with $\mathrm{pH}>3$, but they are sensitive to alkaline sediments with $\mathrm{pH} \geq 8$, and may display dissolution pits and abrasion, which are fairly common in the sample set used in this analysis owing to the near uniformly calcareous bedrock (Cabanes et al. 2011). Re-absorption of phytoliths in silica gel formed by living roots commonly follows dissolution and abrasion previously described, especially in nonarchaeological samples where phytoliths provide a crucial source of silica for plants in soils. The risk of solubility is countered by quick burial of soils, as is the case with archaeological soils.

\section{Aeolian Forces and Phytolith Deposition}

Phytoliths have been shown to be subject to movement by wind forces. This was first demonstrated in the $19^{\text {th }}$ century when Charles Darwin collected dust captured by his sails on The Beagle in 1833, and he and Charles Lyell sent sediment samples to C.G. Ehrenburg to be examined (Twiss 2001). Opal phytoliths were identified in the dust along with pollen, spores, and diatoms, showing that phytoliths could be subject to aeolian forces (Ehrenburg 1847). This effect is such that opal phytoliths have been found in ocean cores in the MidAtlantic Ridge that originated from the savannah environs of Africa (Folger et al. 1967). Phytoliths have also been found to move in higher concentrations during summer months when less moisture is present, although when anomalous winter storms like El Niño take place, dust can also travel trans-continentally (Twiss 2001). Analysis of grass phytoliths from ocean cores near equatorial Africa showed that the most abundant amount of phytoliths was found in the easternmost core, closest to the coast, demonstrating a gradient of the same forces with regularity (DieterHaas et al. 1973; Parmenter and Folger 1974). Phytoliths are dispersed from sediments at an augmented rate by fire combustion. Latorre and colleagues (2012) found that phytoliths are transported in aeolian deposits throughout the year in Argentinian rangelands, with the highest concentration of phytoliths in the month when pasture burning occurs and precipitation is low. If phytoliths feature increased mobility on a macro scale while integrated in soils, phytoliths likely have increased mobility on a micro scale in the laboratory when isolated from other soil components and exposed to fume hood air circulation.

\section{Objectives and Hypotheses}

Despite evidence of phytolith translocation, results of 
these studies are dependent on the assumption that the relative abundances of morphotypes are meaningful. Diverse processes are utilized in the laboratory to extract the silica fraction from other soil components and this process theoretically should increase the rate of mobility of the silica particles, making them vulnerable to local aeolian forces or small amounts of spillage within the laboratory setting (Madella et al. 1998; Parr et al. 2002; Rosen and Weiner 1994). While investigation of phytolith laboratory contamination is infrequent (Hart 2011; Lentfer \& Boyd 1998), there are a number of contamination studies published on other plant proxies: starch grains and pollen. The recommendations prescribed by Loy and Barton (2006) are already implemented in our laboratory, with the exception of sterilizing implements post-use as phytoliths are not destroyed by heat and acid treatments as are starches. Crowther and colleagues (2014) discussed the results of a thorough investigation into how to assess the starch contamination risk in a given laboratory and found that contamination must be monitored regularly. When multiple samples are being processed simultaneously the potential for intra- or cross-study contamination could be significant; the purpose of this study is to explore and quantify this risk. This experiment will determine if contamination is (Hypothesis 1 [H1]) present and (Hypothesis 2 [H2]) if present, is recoverable during counting procedures (Albert and Weiner 2001). In the case that $\mathrm{H} 2$ is not rejected, a rate of contamination can be derived. If contamination is a result of aeolian forces, the fume hood should feature more phytoliths, and the distance from the locus of mounting should correlate with the number of phytoliths deposited.

\section{Methods}

\section{Sampling}

The twelve phytolith samples used had been previously extracted from sediment and purified from clay, carbonates, and organics (Rosen and Weiner 1994). This extraction method involves separating $1 \mathrm{~g}$ (archaeological) or $5 \mathrm{~g}$ (paleoenvironmental) worth of sediment to the $0.25 \mu \mathrm{m}$ size fraction in a sieve thoroughly cleaned with distilled water (Milli-Q Type 1). Hydrochloric acid $(10 \%)$ is added to the sieved sediment in $50 \mathrm{ml}$ tubes, followed by three rounds of centrifugation to remove carbonate material. When vials were exposed on the surface, they were covered with wax to prevent dispersion by aeolian forces.

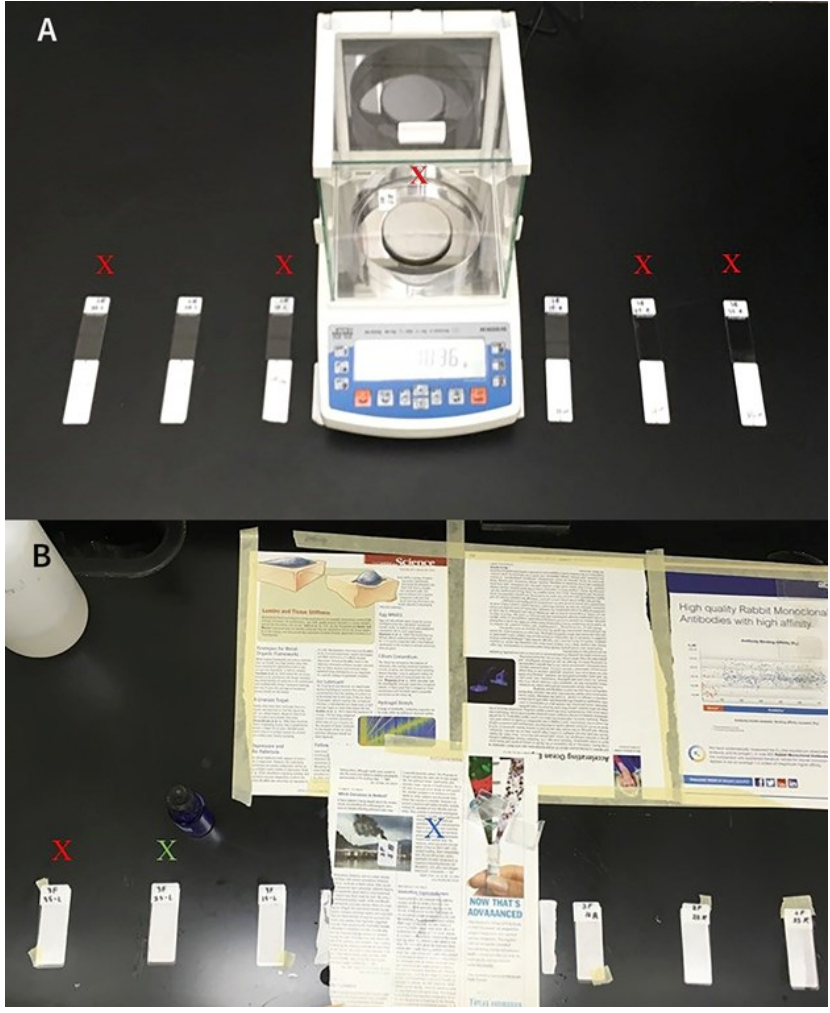

Figure 1 A) Balance setup and B) fume hood setup with $X s$ marking the locations of contamination. The colors refer to the round number: red is round 1 , blue is round 2 , and green is round 3 .

Deflocculation follows with $15 \mathrm{ml}$ of sodium hexametaphosphate applied to the remaining fraction in 600-ml vials. After drying, these samples were scraped and transferred to crucibles for charring at $500^{\circ} \mathrm{C}$ in a muffle furnace for two hours. Following charring, the fraction was added to $15-\mathrm{ml}$ centrifuge tubes with $3 \mathrm{ml}$ of sodium polytungstate. Following heavy-liquid separation, samples were pipetted into 50 $\mathrm{ml}$ vials to dry. After drying and weighing the material in an analytical balance, the remainder was scraped into 1-dram vials. All siphoning was conducted with disposable glass pipettes.

\section{Experiment Design}

In this experiment, we aimed to test the effect of location and distance on risk of contamination. We tested 1) the analytical balance and 2) the fume hood (Figure 1A-B) in The Ohio State University Department of Anthropology Near Eastern Archaeology and Archaeobiology Laboratory (NEAAL). Distance was tested by placing blank slides at intervals of 15,25 , and $35 \mathrm{~cm}$ from the sample 


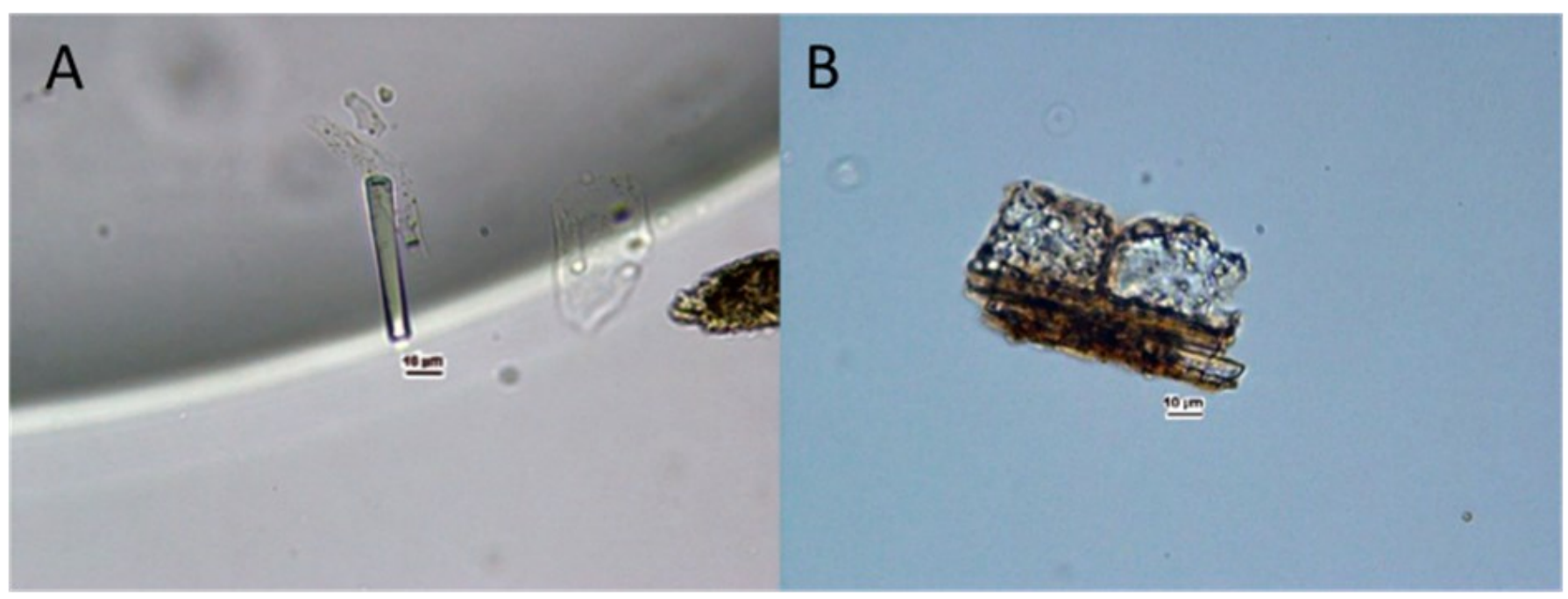

Figure 2 A) A cylindrical rod cell (likely indicative of Cyperaeace) that was found on slide B35R B) A multicell that was found on slide 2F5B. Scale bar equals $10 \mu \mathrm{m}$.

(Figure 1A-B) at both the balance and inside the fume hood, with one set of slides positioned at each distance to the right and left in each area. The maximum distance of $35 \mathrm{~cm}$ was chosen based on the dimensions of the fume hood and the balance counter. An additional slide was placed $5 \mathrm{~cm}$ behind the sample in both locations in order to test contamination at a closer range. The previously extracted samples were placed onto tared, blank slides and massed to approximately two milligrams of phytolith sediment. Each slide containing a recorded mass of sediment was then mounted using six drops of Entellan (Fisher Scientific Rapid Mount 500 ml) and mixed evenly with a toothpick. In our lab, we transfer Entellan into smaller vials for use in mounting. A cover slip was placed on top of each slide and set aside to dry in the fume hood. After each archaeological sample was mounted, the blank contamination slides were then mounted following the same procedure but with two cover slips (one at either end of the slide) instead of one to ensure that any contamination on the slide was captured. This process was repeated three separate times using new slides directly from the package. Furthermore, the test locations were thoroughly cleaned using distilled water and Kimwipes (Delicate Task Wipes 8400/CS) before and after each round, and individuals that prepared the slides wore a lab coat and latex gloves. Following Laurence and colleagues (2011), the general contamination in the lab was tested before and during the mounting process, when four slides with one milliliter of water each were placed in four corners of the laboratory within clean Petri dishes; a single slide was placed inside the fume hood. Each of these slides was left out in the laboratory for five hours which is concurrent with the maximum time required for mounting twelve samples.

\section{Counting}

We used Albert and Weiner's (2001) method for phytolith counting to determine if any crosscontamination was found while scanning transects, which were counted by column at 400x magnification. Four transects were counted for each cover slip based on the previously determined average number of transects needed to count 300 single cells in Manayzah samples. Thus, eight transects in total were counted per slide for contamination slides. Classification of phytolith morphotypes was conducted with the aid of the University of Texas' Environmental Archaeology Laboratory reference slides and PhytCore, a free open-source phytolith database.

In order to quantify a standard contamination rate, we counted the twelve original Manayzah samples in four random transects and calculated a value that accounts for the proportion of contamination in comparison to the total phytoliths that possibly could have resulted in contamination. This contamination rate is a percentage which takes the average number of the phytoliths per slide recovered from the contamination slides, adds this value to the average number of phytoliths per general contamination slide, and divides the sum by the 
Table 1 Summary of phytolith and slide data with respect to round, location, side, and distance. The number of contaminated slides, the number of phytoliths, and the mean number of phytoliths per slide are detailed with respect to variable.

\begin{tabular}{lllll}
\hline Category & Variable & $\begin{array}{l}\text { Contaminated Slides } \\
(\boldsymbol{n})\end{array}$ & $\begin{array}{l}\text { Phytoliths observed } \\
(\boldsymbol{n})\end{array}$ & $\begin{array}{l}\text { Mean number of phytoliths per } \\
\text { slide }\end{array}$ \\
\hline Location & Balance & 5 & 7 & 0.33 \\
& Fume Hood & 3 & 3 & 0.14 \\
\multirow{2}{*}{ Distance } & $5 \mathrm{~cm}$ & 2 & 3 & 0.50 \\
& $15 \mathrm{~cm}$ & 1 & 1 & 0.08 \\
& $25 \mathrm{~cm}$ & 2 & 2 & 0.08 \\
& $35 \mathrm{~cm}$ & 3 & 4 & 0.25 \\
Round & 1 & 6 & 8 & 0.57 \\
& 2 & 1 & 1 & 0.07 \\
& 3 & 1 & 1 & 0.07 \\
Side & Behind & 2 & 3 & 0.50 \\
& Left & 4 & 5 & 0.17 \\
& Right & 2 & 2 & 0.11 \\
\hline
\end{tabular}

average number of phytoliths from the mounted archaeological samples.

\section{Results \\ Initial Findings}

A total of 10 phytoliths were identified on eight out of 42 contamination slides while scanning randomized transects (average $=0.238$ phytoliths per slide). Five slides were from the balance area and three from the fume hood area (Figure 1A-B). Every one phytolith occurrence on a slide when counting to 300 (in this experiment, four transects per cover slip) is extrapolated to account for 7.68 phytoliths if all 2304 fields were counted $(x / 300 * 2304)$; thus, each of the test slides with two cover slips could potentially have approximately 15.36 phytoliths. Those 10 phytoliths on 8 slides may therefore represent 154 phytoliths in total. Eight of the 10 phytoliths were identifiable to type. There were two cylindrical rods (Figure 2A), two bulliforms, a single psilate long cell, a single sinuate long cell, a multicellular leaf/stem of a grass (Figure 2B) and a mesophyll aggregate (Madella et al. 2005). This pattern-the majority of phytoliths found having originated in herbaceous plants-fits the findings of the larger Manayzah study. Additionally, these slides reflected a $\mathrm{D} / \mathrm{P}$ Index (a ratio of scalloped types to Poaceae types) in the same distribution: 0.260 for the mean of the larger study's samples versus 0.125 for the contaminant slides; a chi-square test produced a $p$ value of 0.666 (Alexandre et al. 1997). This result confirms that the contamination slides represent the same population of vegetation as the larger study. As predicted, in the contaminated slides single cells were more common than multicellular types which also fits the results of the larger study: 0.25 (contamination study) vs. 0.237 (broader study) for the ratio of multicells to single cells with a chi-square test producing a $0.347 p$-value. Considering the small number of phytoliths discovered, we used the output of phytolith presence/absence as the dependent variable for our univariate statistical analyses described below.

\section{Statistical Analyses}

Once we found support for $\mathrm{H} 2$, the alternative hypothesis that contaminant phytoliths were detectable through a standard counting protocol, we tested the significance of these results. Our data were limited to 42 observations and were not normally distributed, limiting the number and types of tests we could perform. The observed data were separated into categorical variables of "location" and "distance" (Table 1, Figure 3A-B) in the statistics software SPSS 24. In this experiment, both variables 

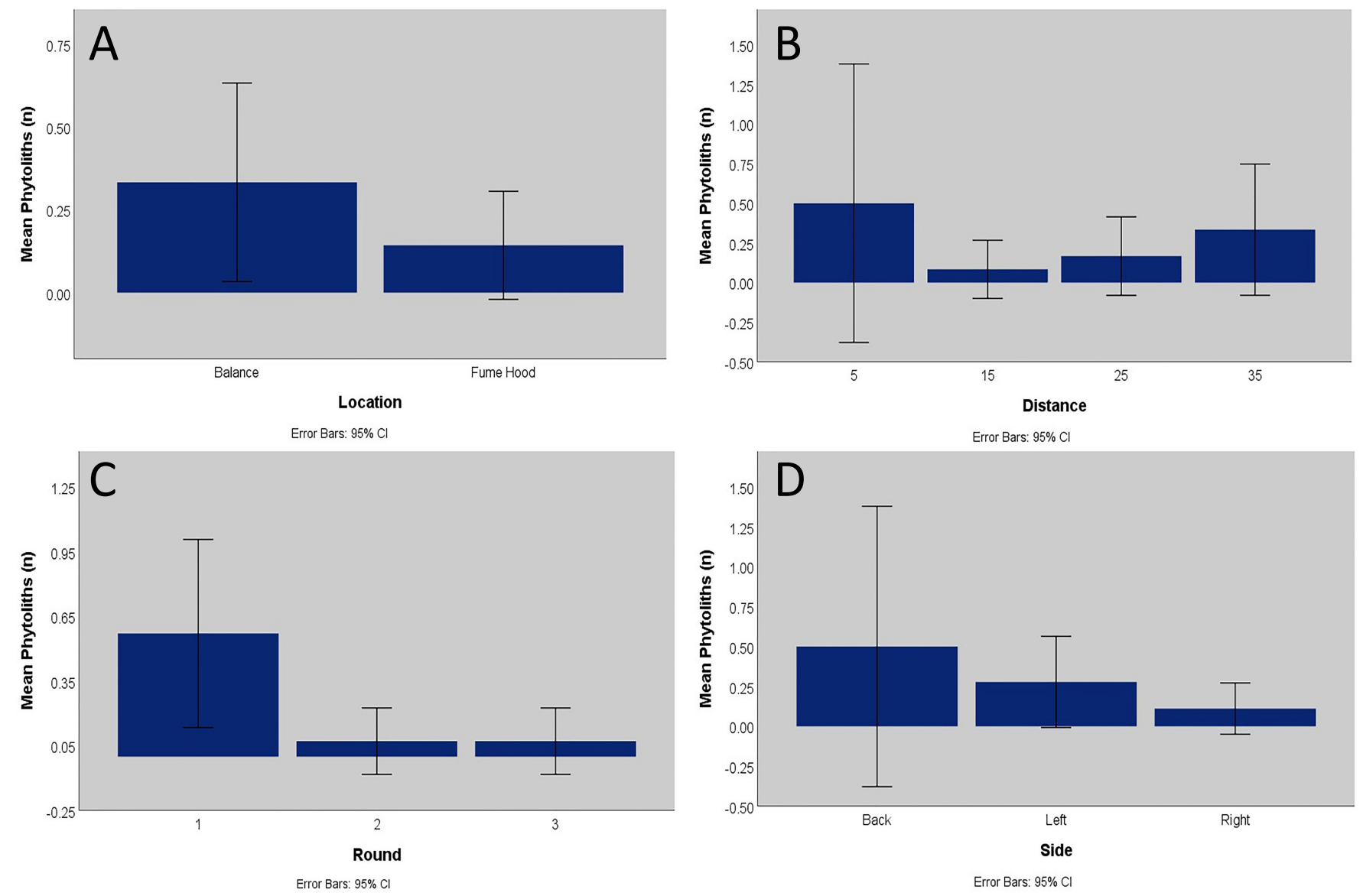

Figure 3 Mean amount of phytoliths with respect to A) location, B) distance, C) round, and D) direction/side. "Round" is the only statistically significant variable ( $p$-value $=0.021)$.

demonstrated patterned results when compared to the presence of phytoliths. However, a chi-square test of each variable produced $p$-values of 0.571 and 0.432 , respectively, showing no statistical significance to these patterns. In contrast with our prediction, the mean number of phytoliths per slide by the balance was higher than the fume hood ( $p$-value $=0.251)$. In addition to the variables of location and distance related directly to our hypothesis, we tested other variables observed during the experiment. When considering distance (centimeters from the center of the mounting slide) as a variable, we also explored the effect of the direction of the slide location relative to the activity locus. The back slide may be favored for more contamination as they are nearest to the locus (5 $\mathrm{cm}$ ) of mounting, but there are a smaller number of slides in this position (6 vs. 18 for the other positions), so contamination here is less likely. It is difficult to disentangle direction from distance in this experiment (Figure 3B-C). Regardless, when tested with a chi-square these patterns did not yield significant results $(p$-value $=0.439)$. Lastly, we considered the variable of "round," as the first round featured eight phytoliths, while the second and third only featured one phytolith each. Analysis of "round" and the presence of phytoliths produced a significant chi-square $(p$-value $=0.021)$. During the first round a somewhat coagulated Entellan mounting medium was utilized and may have played a role in the higher number of phytoliths $(n=8)$ identified in this round versus the other two.

\section{General Contamination}

The results of the four general contamination slides (1 $\mathrm{ml}$ water solution) yielded a single clearly identifiable phytolith: a monocot, multicell type (Figure 4). This contaminant was recovered on the slide located in the corner nearest to the analytical balance where much of the isolated phytolith work is focused. Otherwise, fibers and human hairs were the only other identified 


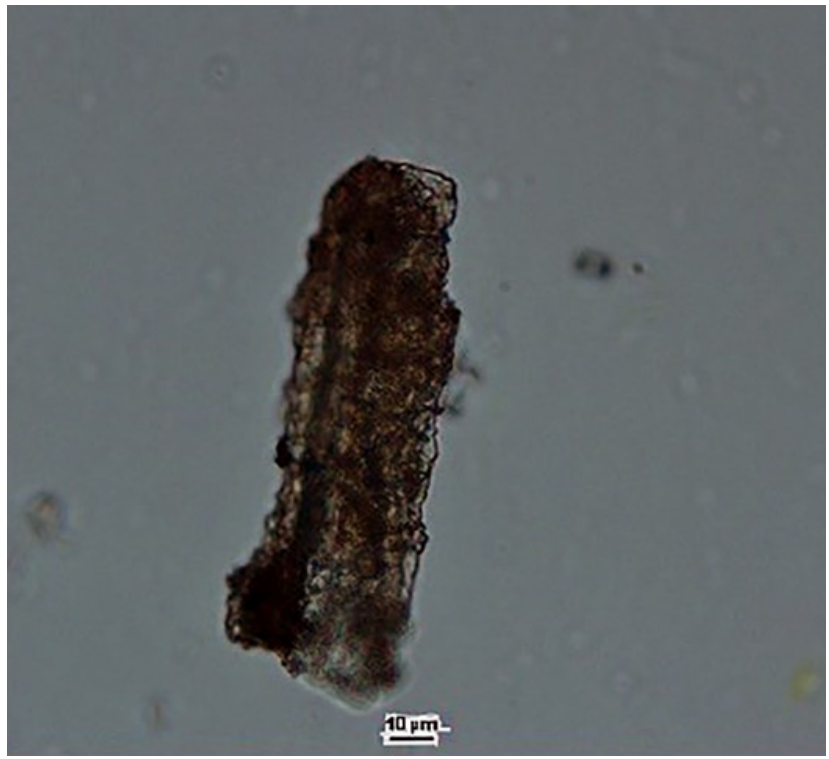

Figure 4 Multicellular phytolith from one general contamination slide. Scale bar equals $10 \mu \mathrm{m}$.

objects on these slides. This result suggests that while there is evidence of general phytolith presence in the environment of the laboratory outside of mounting processes, the incidence of this presence is exceedingly low. Surprisingly, the slides laid out during the mounting process in the same locations as the general contamination test produced zero evidence of phytoliths. This result further suggests that while phytoliths are subject to aeolian force during the mounting process, the material resulting from general contamination outside of a short distance is very low in density. The lack of phytoliths recovered in the fume hood's general contamination slides were particularly indicative of a finding that aeolian forces represent only a minimal force.

\section{Contamination Rate}

In order to factor in the risk of contamination in future analyses, we derived a standard value that utilizes the mean number of phytoliths per slide (mean per slide of the contaminated set + mean per slide of the general contamination set / mean mounted set per slide). The average number of phytoliths per contamination slide was $0.238 \pm 0.082$ per slide and 0.1 for the general contamination slides, whereas the average number of phytoliths for the mounted Manayzah samples was $102.36 \pm 12.46$. The proportion of phytoliths resulting from contamination is thus 0.0033 , which will be applied to future phytolith studies in the laboratory as a measure of material that may be a result of contamination. For example, at the rates of 300 single cells and 100 multicells as are commonly counted, this would equal about one phytolith per slide being of questionable origin (1.32).

\section{Discussion}

Phytoliths were recovered in visual scans and standard transect counts of slides, and are identifiable morphotypes. While contamination was recovered, the variables of location, side, and distance from the center point of the workspace were not correlated with contaminant phytolith density. We initially hypothesized that phytoliths may feature an enhanced aeolian sensitivity when isolated from other soil components in the laboratory (Fishkis et al. 2010a; Parr 2002). We suspected this would be heightened in the fume hood, where circulation of air is continuous and the slides are present for a longer period of time. Our results demonstrate no significant patterning on the variable of location, related to neither presence of contamination nor number of phytoliths, indicating that these aeolian forces do not pose a significant threat to phytolith assemblage integrity. It also appears that human error in the mounting process cannot explain the presence of these phytoliths, either; when accounting for slide position-left, back, or right side of the work area-there were no significant patterns.

Each distance within each location featured at least one contaminated slide and the mean number of phytoliths is not significantly different between $5 \mathrm{~cm}$ and $35 \mathrm{~cm}$ distances (Table 1). This result is dependent on the assumption that the source of contamination is the process of mounting rather than general contaminants in the laboratory. The presence of fibers, skin cells, and non-plant hairs suggest that contamination may have occurred due to contamination from the room's environment in general. However, the results of the general phytolith presence test in the laboratory suggest that while there are phytoliths present in the general atmosphere they are too small in number $(n=1)$ to explain the rate of contamination present on the experimental slides $(\mathrm{n}=8)$. Supporting this hypothesis was the result that "round" demonstrated a significant chi-square for phytolith presence $(p$-value $=0.021)$. The first round had more phytoliths $(\mathrm{n}=8)$ than the following two $(\mathrm{n}=1$ in each). It is possible this is the result of the first round's utilization of a mounting medium that was coagulated. This situation made mounting more difficult, and this may have resulted in enhanced 
contamination with phytoliths possibly being trapped in the material. If coagulated Entellan remains an issue, then mounting this material alone could help determine if phytolith contamination is present within the Entellan itself. The general airborne contaminant experiment demonstrated that while phytoliths are present in dust particles in the lab, the chance of these objects affecting phytolith counts are very low.

In future studies, the use of a staining dye to distinguish between samples may provide further insight into whether the phytoliths come from crosssample contamination or from past studies conducted in the lab (Fishkis et al. 2010a). This study utilized heterogeneous ancient sediments, the most common samples analyzed in this laboratory, but modern plant samples may reflect a narrower suite of possible morphotypes that could be a control for the resulting material collected (pers. comm., J. Marston). It is also likely that reference material may feature higher deposition into the circulated air flow if these samples are treated by the dry-ashing method; we know combustion increases the release of phytoliths (Latorre et al. 2012). These tests would allow us to achieve a better understanding of how phytoliths move and become archived in the laboratory. This study only tested the mounting step in the extraction process, although contamination may come into the sample at other steps, such as during the transfer to $15-\mathrm{ml}$ centrifuge tubes for separation from the crucibles following oxidation.

The rate of contamination our calculation derived (0.0033) provides us with a measure of potential for contamination during phytolith sample mounting: about one phytolith per slide when standard quantities are counted. We can use this value as a threshold at which evidence of potential domesticates or nonnative morphotypes can be measured against. We will also place a blank slide at the balance during future mounting to test the continued threat of contamination present in this location. While the measure itself is low, and the evidence of general phytolith content in the laboratory is lower still, we would recommend such an experiment being tested in each laboratory setting in order to assess the unique contamination risk present based on different protocols and different general cleanliness exhibited here.

\section{Conclusion}

The goal of this study was to determine whether distance or location within work areas was more likely to correlate to higher phytolith mobility and cause problems of cross-contamination. While the finding of contamination in this study cannot be explained by distance or location alone, it is clear that within $35 \mathrm{~cm}$ a risk of cross-contamination is present and has the potential to affect phytolith counts and interpretation. The number of phytoliths recovered per slide was low. A maximum of two were found per slide, which represent up to 5.71 per cover slip area using our quantitative method (Albert \& Weiner 2001). If these contaminants are morphotypes common to samples being analyzed from the same site, their presence is relatively inconsequential. For example, on a slide on which 300 single-cells are counted, containing 125 psilate long cells and 75 bulliforms, seven more of each morphotype would not greatly change interpretation of the assemblage. However, when processing samples from different archaeological sites or geographical regions, such a chance of contamination has the potential to affect ecological reconstruction or even vegetation history. The possibility of erroneously detecting the first domesticate in a region due to contamination between different temporal layers or geographical areas is of great concern. It is of utmost importance that thorough cleaning take place before and after weighing and mounting. We recommend that when conducting concurrent phytolith mounting processes a distance greater than $35 \mathrm{~cm}$ is utilized, temporal sequences are restricted, and samples from different regions are not processed simultaneously. Due to the results of this study, this laboratory will hereto utilize a proportional measure (0.0033) as a phytolith threshold when encountering possible evidence of domesticates or unexpected foreign taxa. We propose that fellow phytolitherians conduct a similar preliminary test of the phytolith contamination vulnerability in their laboratory spaces. If rates derived are higher than one percent of the total phytoliths counted, we would suggest efforts are extended to reduce the effect of contamination (e.g., keep blank slides more than $35 \mathrm{~cm}$ away from the locus of mounting, regularly check dust input, move all soils to a different space).

\section{Acknowledgements}

We would like to acknowledge the funding provided for this project's laboratory space by The Larsen Research and Travel Grant in 2015 and the National Science Foundation Dissertation Improvement Grant in 2016. We would like to acknowledge Thomas C. 
Hart, Arlene Rosen, and Mark Hubbe for sharing ideas and feedback in the development of this experiment's research design and in testing its robustness. We would lastly like to thank Joy McCorriston and Kristen Gremillion for supporting our research program in paleoethnobotany.

\section{Declarations}

Sources of Funding: National Science Foundation Doctoral Dissertation Improvement Grant; Larsen Travel and Research Grant; Alumni Grants for Graduate Research and Scholarship.

\section{References Cited}

Albert, R.M. and S. Weiner. 2001. Study of Phytoliths in Prehistoric Ash Layers from Kebara and Tabun Caves. In Phytoliths: Applications in Earth Science and Human History, edited by J. D. Meunier and F. Colin, pp. 251-266. A.A. Balkema Publishers, Lisse, Netherlands.

Alexandre, A., J.D. Meunier, A.M. Lézine, A. Vincens, and D. Schwartz. 1997. Phytoliths: Indicators of Grassland Dynamics during the Late Holocene in Intertropical Africa. Palaeogeography, Palaeoclimatology, Palaeoecology 136:213-229. DOI:10.1016/S00310182(97)00089-8.

Buffington, A., M.J. Harrower, J. McCorriston, E.A. Oches. 2017. A Niche Construction Approach to Vegetation Community Development in the Southwest Arabian Neolithic: Preliminary Results. Proceedings of the Seminar for Arabian Studies. 47:3142.

Cabanes, D., S. Weiner, and R. Shahack-Gross. 2011. Stability of Phytoliths in the Archaeological Record: A Dissolution Study of Modern and Fossil Phytoliths. Journal of Archaeological Science 38:24802490. DOI:10.1016/j.jas.2011.05.020.

Crassard, R., J. McCorriston, E. Oches, A. Bin 'Aqil, J. Espange, and M. Sinnah. 2006. Manayzah, Early to Mid-Holocene Occupations in Wadi Sana (Hadramawt, Yemen). Proceedings of the Seminar for Arabian Studies 36:151-173.

Crowther, A., M. Halsam, N. Oakden, D. Walde, and J. Mercader. 2014. Documenting Contamination in Ancient Starch Laboratories. Journal of Archaeological Science 49:90-104. DOI:10.1016/j.jas.2014.04.023.

Diester-Haas, L., H.J. Schrader, and J. Thiede. 1973. Sedimentological and Paleoclimatological Investigations of Two Pelagic Ooze Cores Off
Cape Barbas, Northwest Africa: "Meteor" ForschErgebnisse. Reibe C. 16:19-66.

Ehrenberg, C.G. 1847. Passatstaub und Blutregen: Ein Großes Organisches Unsichtbares Wirken und Leben in der Atmosphäre. In Abhandlung der Königlichen, edited by Deutsche Akademie der Wissenschaften zu Berlin, pp. 269-460. Verlag der Königlichen Akademie der Wissenschaften, Berlin.

Folger, D.W., L.H. Burkle, and B.C. Heezen. 1967. Opal Phytoliths in a North Atlantic Dust Fall. Science 155:1243-1244. DOI:10.1126/ science.155.3767.1243.

Fishkis, O., J. Ingwersen, M. Lamers, D. Denysenko, and T. Streck. 2010a. Phytolith Transport in Soil: A Laboratory Study on Intact Soil Cores. European Journal of Soil Science 61:445-455. DOI:10.1111/ j.1365-2389.2010.01257.x.

Fishkis, O., J. Ingwersen, M. Lamers, D. Denysenko, and T. Streck. 2010b. Phytolith Transport in Soil: A Field Study Using Fluorescent Labelling. Geoderma 157:27-36. DOI:10.1016/ j.geoderma.2010.03.012.

Gobetz, K.E. and S.R. Bozarth. 2001. Implications for Late Pleistocene Mastodon Diet from Opal Phytoliths in Tooth Calculus. Quaternary Research 55:115-122. DOI:10.1006/qres.2000.2207.

Gol'yeva, A.A., A.L. Aleksandrovskiy, and L.K. Tselishcheva. 1995. Phytolithic Analysis of Holocene Paleosoils. Eurasian Soil Science 27: 46-56.

Hart, T. 2011. Evaluating the Usefulness of Phytoliths and Starch Grains Found on Survey Artifacts. Journal of Archaeological Science 38:3244-3253. DOI:10.1016/j.jas.2011.06.034.

Horrocks, M. 2005. A Combined Procedure for Recovering Phytoliths and Starch Residues from Soils, Sedimentary Deposits and Similar Materials. Journal of Archaeological Science 32:1169-1175. DOI:10.1016/j.jas.2005.02.014.

Latorre, F., M.F. Honaine, and M.L. Osterrieh. 2012. First Report of Phytoliths in the Air of Argentina. Aerobiologia 28:61-69. DOI:10.1007/s10453-0119211-5.

Laurence, A.R., A.V. Thoms, V.M. Bryant, and C. McDonough. 2011. Airborne Starch Granules as a Potential Contamination Source at Archaeological Sites. Journal of Ethnobiology 31:213-232. DOI:10.2993/0278-0771-31.2.213. 
Loy, T.H. and H. Barton. 2006. Post-Excavation Contamination and Measures for Prevention. In Ancient Starch Research, edited by R. Torrence and H. Barton, pp. 165-167. Left Coast Press, Walnut Creek, CA.

Madella, M. and C. Lancelotti. 2012. Taphonomy and Phytoliths: A User Manual. Quaternary International 275:76-83. DOI:10.1016/j.quaint.2011.09.008.

Madella, M., A. Alexandre, and T. Ball. 2005. International Code for Phytolith Nomenclature 1.0. Annuals of Botany 96:253-260. DOI:10.1093/ $\mathrm{aob} / \mathrm{mci172.}$

Madella, M., A.H. Powers-Jones, and M.K. Jones. 1998. A Simple Method of Extraction of Opal Phytoliths from Sediments Using a Non-Toxic Heavy Liquid. Journal of Archaeological Science 25:801803. DOI:10.1006/jasc.1997.0226.

McCorriston, J., D.E. Walter, E.A. Oches, and K.L. Cole. 2002. Holocene Paleoecology and Prehistory in Highland Southern Arabia. Paléorient 28:61-88.

Okamoto, G., T. Okura, and K. Goto. 1957. Properties of Silica in Water. Geochimica et Cosmochimica Acta 12:123-132. DOI:10.1016/00167037(57)90023-6.

Parmenter, C. and D.W. Folger. 1974. Eolian Biogenic Detritus in Deep Sea Sediments: A Possible Index of Equatorial Ice Age Aridity. Science 185:695-698. DOI:10.1126/ science.185.4152.695.

Parr, J.F. 2002. A Comparison of Heavy Liquid Flotation and Microwave Digestion Techniques for the Extraction of Fossil Phytoliths from Sediments. Review of Palaeobotany and Palynology 120:315-336. DOI:10.1016/S0034-6667(01)001385.

Parr, J.F., V. Dolic, G. Lancaster, and W.E. Boyd. 2001. A Microwave Digestion Method for the
Extraction of Phytoliths from Herbarium Specimens. Review of Palaeobotany and Palynology 116:203-212. DOI:10.1016/S0034-6667(01)000896.

PhytCore DB: Powered by ArcheoScience. PhytCore [web page]. URL: http://www.phytcore.org/ phytolith/index.php. Accessed on March 23, 2017.

Piperno, D.R. 2006. Phytoliths: A Comprehensive Guide for Archaeologists and Paleoecologists. AltaMira Press, Lanham, MD.

Rovner, I. 1983. Plant Opal Phytolith Analysis: Major Advances in Archaeobotanical Research. Advances in Archaeological Method and Theory 6:225-266. DOI:10.1016/B978-0-12-003106-1.50011-0.

Rosen, A.M. 1992. Preliminary Identification of Silica Skeletons from Near Eastern Archaeological Sites: An Anatomical Approach. In Phytolith Systematics: Emerging Issues, edited by G. Rapp, Jr. and S.C. Mulholland, pp. 129-147. Plenum Press, New York, NY.

Rosen, A.M, and S. Weiner. 1994. Identifying Ancient Irrigation: A New Method Using Opaline Phytoliths from Emmer Wheat. Journal of Archaeological Science 21:125-132. DOI:10.1006/ jasc.1994.1013.

Tsartsidou, G., S. Lev-Yadun, R. Albert, A. MillerRosen, N. Efstratiou, and S. Weiner. 2007. The Phytolith Archaeological Record: Strengths and Weaknesses Evaluated Based on a Quantitative Modern Reference Collection from Greece. Journal of Archaeological Science 34:1262-1275. DOI:10.1016/j.jas.2006.10.017.

Twiss, P. 2001. A Curmudgeon's View of Grass Phytolithology. In Phytoliths: Applications in Earth Sciences and Human History, edited by J. D. Meunier and F. Colin, pp. 7-25. A.A. Balkema Publishers, Lisse, Netherlands. 